Teoría y aplicaciones semióticas

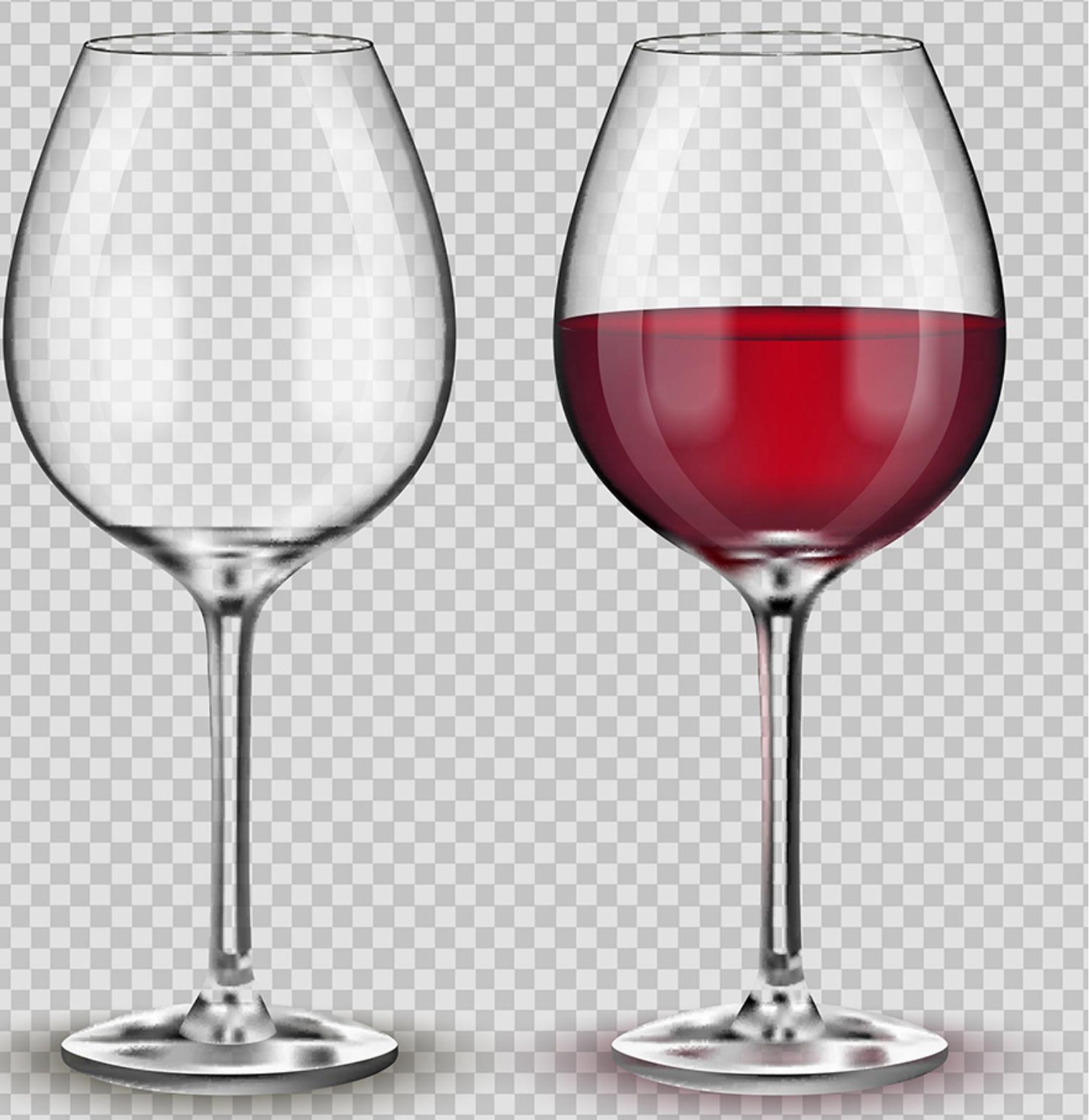





\title{
Análisis del curso de acción de las prácticas*
}

\author{
Jacques Fontanille \\ (Universidad de Limoges - Instituto Universitario de Francia)
}

Recibido: $11 / 1 / 2016$

Aprobado: 8/3/2016

\begin{abstract}
Resumen: Este ensayo semiótico indaga la producción del sentido en el curso mismo de la acción. Como se trata de un curso abierto, es relevante la naturaleza y el horizonte proyectivo, lo que nos ubica en el terreno de la acción como lenguaje y en los arreglos sintagmáticos necesarios para mantener la congruencia. Para lograrlo, el curso de acción tendrá que acudir a la acomodación, la regulación, el ajuste, la memoria y la anticipación, entre otros mecanismos; por ejemplo, toda una tipología de las huellas nos lleva de las formas a los procesos interpretativos, así como a la concordancia o discordancia y a las reglas de interpretación.

Palabras clave: sintagmática / isotopía / articulaciones modales / huella / acomodación / concordancia / discordancia
\end{abstract}

\section{Analysis of the Course of Action in Practices}

Summary: This is a semiotic essay in which the production of meaning is analyzed during the course of action. As it is an opened course, its nature and projective scope are relevant, which places us in the action field as language, and also in the syntagmatic settings needed to maintain the congruence. In order to achieve it, the course of action would have to use adaptation, regulation, adjustment, memory and anticipation, etc. For example, there is a typology of traces which leads us from the forms to the interpretative processes, as well as to the concordance or discordance, and to the interpretation rules.

Key words: syntagmatic / isotopes / modal articulations / trace / adaptation / concordance / discordance

* Traducción: Desiderio Blanco. 


\section{Introducción}

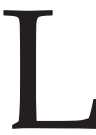

a cuestión está planteada: ¿puede la semiótica interesarse útilmente por las prácticas en cuanto tales, es decir, consideradas como cursos de acción abiertos y fluctuantes?

La pregunta es arriesgada en la medida en que toda la metodología semiótica de inspiración greimasiana reposa en el principio de la textualidad, es decir, en un tipo de semióticas-objetos cerradas, acabadas y estabilizadas, a diferencia de la semiótica peirciana, que reposa en el principio de la interpretación infinita. Las únicas aberturas que se les ha otorgado a esas semióticas-objetos cerradas son, por un lado, la pluri-isotopía, y, por otro lado, la intertextualidad, que abre cada semiótica-objeto a la diversidad de conexiones con otras semióticas-objetos, con co-textos y con otros contextos.

Sin embargo, esa pregunta merece ser planteada y sometida a debate en el seno mismo de las semióticas con vocación textual. Si las expresiones «enunciación en acto», "praxis enunciativa», «semiosis viviente» tienen algún sentido, ese no puede ser sino el sentido de un curso fluctuante que, justamente, en el desarrollo sintagmático mismo busque su significación, la cual se esfuerza por estabilizar y que la construye en interacción permanente con otros cursos de acción y con otras prácticas.

La propuesta que consiste en distinguir varios niveles de pertinencia del plano de la expresión (a los que corresponden otros tantos "planos de inmanencia») tiene ya por objeto abrir la investigación semiótica más allá de los límites del texto, definiendo al mismo tiempo el lugar del texto en un conjunto más amplio. Pero esa propuesta no es pertinente si no logra asumir la diferencia de constitución semiótica de cada uno de esos planos, ni convencerse de que las significaciones respectivas de un signo, de un texto, de un objeto, de una práctica, de una estrategia o de una forma de vida, se dan a captar bajo especies diferentes y por métodos y operaciones, en parte al menos, también diferentes. La demostración de esas diferencias de pertinencia ha sido hecha en otro tiempo por el signo y por el texto. Hay que intentar hacerla por medio de las prácticas, así como por los otros tipos de semióticas-objetos, cuya lista no está necesariamente cerrada.

\section{Las prácticas como lenguajes}

El semiotista no se interesa en las prácticas en general, sino en aquellas que producen sentido y en cuanto configuran un tipo particular de semióticas-objetos. La especificidad del acercamiento semiótico, entre todos los otros de las ciencias humanas y sociales, implica que toda tentativa de comprensión y de interpretación de cualquier objeto de estudio responda a dos preguntas previas:

i) ¿La comprensión del objeto de estudio tiene una forma específica que 
produce significación, que contiene valores, y que constituye por eso un «objeto semiótico»?

ii) ¿Cuál es el «modus operandi» de la producción o de la generación de esa significación y de esos valores?

En respuesta a esas dos preguntas, el analista se interesará entonces, a la vez, por las propiedades características de la relación semiótica y por el proceso de constitución de su significación.

\section{La significación de un curso de acción}

Por lo que concierne a las prácticas, precisamente, lo que hace la diferencia con el acercamiento del sociólogo o del etnólogo es: (i) por un lado, que las prácticas solamente pueden considerarse «semióticas» en la medida en que, como mínimo, estén constituidas por un plano de la expresión y por un plano del contenido; (ii) por otro lado, que produzcan algún tipo de significación en la exacta medida en que una práctica es una organización de acciones que construye con su movimiento mismo la significación de una situación $\mathrm{y}$ de sus transformaciones.

A diferencia de una acción textualizada y terminada, cuya significación está totalmente contenida en el sentido del objeto que ha tenido en la mira, la acción (el objeto de valor), una acción, considerada en su curso práctico, debe su significación al ordenamiento mismo del curso de esa práctica. En otros términos, el proceso de producción de esa significación radica en la organización sintagmática misma. Inversamente, buscar el sentido puesto en la mira y clausurado de una acción en curso, focalizado en el objeto de valor, se reduce a tratarla como un texto narrativo.

El mismo objeto de análisis puede recibir los dos tipos de aproximación, alternativa o sucesivamente, lo cual supone que se acepta la especificidad y la complementariedad de ambos puntos de vista metodológicos diferentes. El punto de vista textual parte del principio según el cual la clausura es por sí misma significante, y especialmente el "final" de un relato es portador de la "última palabra" de la historia, y que, por lo mismo, cierra la significación sobre sí misma. El punto de vista práctico [de la práctica] parte del principio según el cual los eventuales límites y marcos del objeto no son en sí mismos significantes, y que es preciso buscar el sentido en las articulaciones del "curso de acción" en cuanto curso.

Por consiguiente, es posible tratar un texto o una pintura bajo el punto de vista práctico, focalizando el «modus operandi» de su producción o de su interpretación, sin tomar como pertinente el hecho de que ese texto o esa pintura estén «terminados». De la misma manera, es igualmente posible «textualizar» una conversación, una práctica de juego o cualquier otra secuencia de "curso de acción", decidiendo que los límites son ahora pertinentes y que van a contribuir a la constitución de un sentido global del objeto. 
El hecho de que el curso de acción de las prácticas cotidianas esté con frecuencia cerrado por razones de compatibilidad con otras prácticas concurrentes, a veces por simples razones culturales, no es un argumento contra su tratamiento en cuanto prácticas. Una comida tiene necesariamente un comienzo y un fin (aunque la costumbre de comer cualquier cosa al paso está rompiendo la norma cultural), pero eso no significa que el análisis deba considerar necesariamente esos dos límites como pertinentes para su significación. Pueden serlo evidentemente en la perspectiva de una «textualización» o de una «narrativización» de la comida; pero pueden no serlo en la perspectiva de una "práctica de la comida».

Haremos la hipótesis de que las prácticas significantes se caracterizan y se distinguen principalmente por el rol del curso de acción en la producción de formas significantes y específicamente de valores prácticos, suscitados y expresados por la forma de los cursos de acción, con el «grano» más fino de su despliegue espacial, temporal, aspectual, modal y pasional.

El valor de las prácticas no se lee en el contenido de los objetos puestos en la mira, a diferencia del hacer narrativo textualizado y considerado como el resultado de una transformación elemental. Este último, en efecto, se interpreta a partir de la confrontación entre una situación final y una situación inicial, y, desde ahí, la significación y los valores implicados en cada una de las etapas del recorrido deben ser deducidos exclusiva y retrospectivamente a partir de los valores puestos en juego en esa transformación constatada. El detalle de las «peripecias» y las modulaciones de los arreglos estratégicos y tácticos del curso de acción no afectan en nada dicha significación.

En cambio, los valores de una práctica no pueden ser deducidos retrospectivamente a partir de una transformación constatada in fine, porque una práctica es un desarrollo abierto al comienzo y al final, que no ofrece ningún asidero para una confrontación entre una situación inicial y una situación final. Si las prácticas no tienen, propiamente hablando, «objetos de valor», tienen sin embargo «objetivos» $\mathrm{y}$ «horizontes de referencia» axiológica. Un «objetivo» es ciertamente puesto en la mira, pero ese objetivo se diferencia de un «objeto de valor» al menos por dos razones:

i) Un objetivo es de naturaleza proyectiva: la acción lo construye en su curso mismo, mientras que un «objeto de valor» solo puede ser firme y retrospectivamente determinado por confrontación de la situación final con la situación inicial.

ii) Un objetivo es siempre revisable y adaptable: por definición, como es de naturaleza proyectiva, participa de las regulaciones de la acomodación sintagmática que él determina, pero de la que recibe en retorno diversas inflexiones. Un objetivo solo se refiere a sistemas de valores 
abiertos y provisionales, que dependen de las fluctuaciones de los valores en curso de acción.

Los valores práxicos pueden ser captados a través de las formas modales, sensibles y pasionales, temporales y espaciales, aspectuales y rítmicas de la organización sintagmática del proceso, principalmente, y secundariamente, a través de los valores semánticos implicados provisionalmente en el contenido de su objetivo u objetivos.

La evocación de los estados sensibles y pasionales del curso de acción incita a volver sobre un malentendido que se produjo con las primeras formulaciones de la semiótica de las pasiones: en aquellas primeras formulaciones, en efecto, pudo dejarse entender que la sintagmática de las pasiones podía ser tratada de la misma manera que la de la acción, con el mismo tipo de modelos y de esquemas canónicos, y que las pasiones eran completamente «textualizables». Hoy ya sabemos que una pasión o una experiencia sensible son procesos abiertos, ritmados y escondidos, con momentos fuertes y momentos débiles, con impulsos y latencias, pero jamás cerrados y totalmente textualizables.

\section{Reglas del desarrollo sintagmático}

Por lo demás, si las prácticas pueden ser calificadas de «semióticas», deben poder ser asimiladas a un «lenguaje», y un lenguaje no se reduce al hecho de que debe estar dotado de un plano de la expresión y de un plano del contenido. Por cierto, la identificación de esos dos planos y la de su correlación es un mínimo necesario y una de las primeras tareas por cumplir consiste justamente en la identificación y en la descripción del «plano de la expresión» propio de la práctica en estudio y de sus relaciones con otros planos de la expresión. Pero para que podamos hablar de «lenguaje», y sin que sea necesario identificar cualquier cosa como una «lengua» dotada de una «gramática», hace falta, no obstante, que existan allí códigos y normas que guíen en cierto modo la atribución de valor a las formas sintagmáticas.

Y las prácticas no carecen ni de unos ni de otras, los cuales determinan las opciones axiológicas entre las «maneras de hacer» $y$ entre las articulaciones prácticas: por ejemplo, en el caso de las prácticas profesionales, las deontologías definen el marco ético dentro del cual pueden desenvolverse los "saber-hacer" y sus aprendizajes. Las prácticas científicas están igualmente reguladas por códigos de cientificidad, con protocolos establecidos y por una deontología. Otras prácticas estarán también reguladas por códigos de estética. Poco importa, puesto que se construyen primero sobre el fondo de valores de contenido asociados a expresiones de naturaleza sintagmática, es decir, de naturaleza ética.

Si el valor de las prácticas pudiera leerse dentro de una clausura textual, 
no sería necesario acompañarlas de una deontología, pues sería suficiente con asegurar que el contenido de los valores adquiridos o transformados es conforme con el sistema de valores de referencia. Pero eso no es suficiente, y el debate ético multisecular entre las teleologías y las deontologías da testimonio de eso: en efecto, en nombre de los valores teleológicos (o sea escatológicos) -aquellos que solamente se pueden alcanzar al fin de un recorrido concluido- se pueden cometer los peores abusos; y cultivar las prácticas menos aceptables, esta vez en nombre de valores deontológicos.

El ethos reproduce, pues, en su propia dimensión, la distinción entre dos puntos de vista: puede, en efecto, constituirse a partir de resultados y desenlaces a los que se llega al final del recorrido (para una «teleología» es la palabra «fin» la que encierra el sentido del recorrido); pero también, como lo han puesto de relieve todos los retóricos desde largo tiempo atrás, a partir del detalle de los comportamientos intermedios, de los argumentos utilizados, y más generalmente de las maneras de conducir el curso de acción (para una «deontología», es el detalle de los procedimientos el que conlleva el sentido del recorrido).

Lo que caracteriza, pues, a las prácticas en cuanto "lenguajes" (es decir, en cuanto semióticas-objetos), son los arreglos sintagmáticos que aceptan o que rechazan, que son requeridos o excluidos, deseados o desdeñados. Su plano de la expresión estará cons- tituido por las articulaciones sintagmáticas directa o indirectamente observables, y su plano del contenido consistirá en las modalizaciones según el poder-ser, el deber-ser, el quererser, y el saber-ser, que caracterizan a su vez las apreciaciones eufóricas o disfóricas, así como los efectos pasionales asociados a las fluctuaciones del curso de acción. En esta perspectiva, los «usos prácticos», en cuanto arreglos sintagmáticos del plano de la expresión, están correlacionados en el plano del contenido con polaridades modales, axiológicas y pasionales que fundamentan las elecciones sintagmáticas, y cada uno de esos arreglos elegidos (en la expresión) remite a valores específicos (en el contenido). Tal es la relación semiótica específica (e inmanente al curso de acción) que tenemos en la mira aquí mismo.

\section{Los valores práxicos}

Las prácticas son lenguajes específicos, cuyas opciones sintagmáticas reposan en un sistema de valores propios, en pocas palabras, un sistema de valores práxicos.

Además, las opciones sintagmáticas propias de las prácticas, efectuadas durante los cursos de acción abiertos, manipulan reglas, normas y códigos en todo punto de la cadena sintagmática, en las dos direcciones de esa cadena: regresiva y progresiva, y bajo una doble determinación: externa e interna.

Respecto a las dos direcciones (regresiva y progresiva), el razonamiento 
que convendría desarrollar aquí debería parecerse a aquel que Gustave Guillaume desarrolló al describir la evolución coordinada de los dos quanta tensivos que componen un proceso en curso de desarrollo: un quantum de tensión y un quantum de distensión. Guillaume explica que en cada momento del proceso, el equilibrio entre los dos quanta evoluciona de manera solidaria e inversa a la vez, desde el comienzo del proceso en que la tensión es máxima y la distensión nula, hasta el fin del proceso en que la distensión es máxima y la tensión nula. Los valores nulos (sea los de la distensión o los de la tensión) proporcionan la definición de los límites inicial y final.

En una práctica, el curso de acción ha de ser tratado en principio como abierto, los valores iniciales y finales no pueden ser nulos; en cambio el principio de antagonismo y de solidaridad funciona plenamente. Además, no se trata aquí de tensiones y de distensiones en el sentido de Guillaume, pues él no se interesa más que en el desarrollo de un proceso cualquiera. Para nosotros, de lo que se trata es de la capacidad de un curso de acción para construir y descubrir su propia significación, y, en general, de la extensión o de la reducción de los posibles, de los conocibles, o incluso de los deseables de la acción. Dicho de otro modo, lo que está en juego en el desarrollo sintagmático es la elección modal, es la invención y la selección de las articulaciones semánticas dominantes de la acción.
Podríamos, para simplificar la exposición, atenernos al «poder-ser». En todo punto de la cadena, el operador debe tratar regresiva y progresivamente la contingencia y la posibilidad de las opciones que se le presentan, de la necesidad y del azar, etc. Él construye en cada punto la significación de todas las modalizaciones que afecten y determinen las organizaciones sintagmáticas, o más llanamente, las peripecias de la acción. Debe, pues, modalizar y evaluar las articulaciones anteriores y las ulteriores, reconstruir la coherencia eventual y las regularidades de las primeras, deducir de ahí las posibilidades que quedan abiertas para las segundas, e incluso, si es posible, preverlas.

Los dos quanta solidarios serían en el caso del «poder-ser» la contingencial posibilidad por un lado, y la significación/coherencia, por otro lado. Cuanto más abiertos son los posibles, menos accesible es la significación de la práctica; cuanto más dispersiva es la obra de la contingencia, menos adquirida parece la coherencia del curso de acción. El mismo razonamiento podría hacerse a propósito del «saber-ser»y del «querer-ser».

Esta propuesta se deriva, en parte, de una hipótesis más general formulada en Semiótica de las pasiones, a propósito de la generación de la significación a partir de la «masa tímica»: en el nivel más profundo, la masa de los flujos y tensiones disponibles es máxima, y las articulaciones son mínimas; a me- 
dida que se progresa en los niveles del recorrido generativo, el número y la consistencia de las articulaciones significantes aumentan, al mismo tiempo que el potencial de las tensiones disponibles disminuye. Esta descripción es «generativa»y no «sintagmática», pero la transposición a la sintagmática de las prácticas es no obstante legítima, ya que se trata siempre de un proceso de constitución de la significación.

Globalmente, el sentido del curso de acción se construye por la negación, de una parte, del campo de modalización, y de otra parte, por la selección. Esta «reducción» es provisional, puesto que en un curso de acción abierto por ambos lados, los posibles seleccionados y explotados lo son siempre en número indeterminado: esto sería en suma una «negatividad» sin esperanza de clausura.

\section{Puntos críticos y marcajes: hacia una semiótica de la huella}

La diferencia con la evolución de un proceso según G. Guillaume, consiste en que la progresión no es, en la perspectiva de las prácticas, lineal: en todo punto de la cadena, los equilibrios solidarios y antagonistas entre las dos tensiones pueden invertirse, la evolución puede seguir una nueva tendencia; y es justamente esta propiedad la que transforma el curso abierto de las acciones prácticas en una secuencia virtualmente continua de zonas críticas, a partir de las cuales se forman arreglos sintagmáticos reconocibles, prospectiva o retrospectivamente. La identificación de las zonas críticas, de las «singularidades» del curso de acción constituye, pues, la primera tarea por cumplir, ya que esos puntos críticos dan acceso a los segmentos y a las formas sintagmáticas pertinentes.

En una perspectiva textual, los límites inicial y final de la clausura narrativa definen el perímetro del análisis, dentro del cual los modelos son pertinentes. En la perspectiva de las prácticas, las zonas críticas del curso de acción juegan el mismo rol. $\mathrm{Y}$ a fin de funcionar como criterio de pertinencia para la acomodación sintagmática, deben ellas mismas ser seleccionadas y marcadas. En otros términos, necesitamos comprender cómo se pasa de un curso de acción virtualmente continuo, pero insignificante, a una serie actualizada, marcada, discontinua y significante.

La semiótica de las prácticas tiene que elaborar una teoría de los «marcajes» sintagmáticos, de esos marcajes que se supone que determinan los «puntos críticos pertinentes», a partir de los cuales se reorganiza el curso de la práctica, entre la reducción de los campos de modalización, por un lado, y las acomodaciones significantes y coherentes, por otro lado. Para distinguirlos del conjunto de todos los puntos virtuales, deben estar marcados, es decir, llevar un acento, una sobredeterminación de naturaleza pasional, espacio-temporal, modal y sensible. 
Como los participantes que interactúan en el curso de una práctica son cuerpos-actantes (y no simples posiciones o roles formales narrativos), el marcaje de un punto crítico en el curso de acción no puede ser tratado como una simple marca formal y abstracta: debe corresponder a una huella, a un marcaje corporal.

Para lograrlo, la huella ha de obedecer a dos exigencias complementarias: (i) debe, de alguna manera, poder ser aprehendida como una transposición en el plano figurativo y corporal, de las propiedades de los «puntos críticos pertinentes» para la acomodación sintagmática, y (ii) en consecuencia, debe ser, al menos en parte, isomorfa de los segmentos de acomodación práctica. La primera exigencia es cumplida por la relación entre inmanencia y manifestación. La segunda condición se cumple por la estructura regresiva y progresiva, común a los dos niveles del análisis.

En cuanto a la condición de isomorfismo, queda cumplida en la medida en que una huella es el resultado de interacciones anteriores, de las cuales da testimonio e indica que han sido actualizadas en detrimento de todas las otras que no han dejado trazas. Además, prepara las interacciones ulteriores, proporcionándoles un conjunto de determinaciones semióticas (espacio-temporales, aspectuales, modales, sensibles, pasionales, etc.) a las cuales deberán confrontar y adaptarse.

En lo que se refiere a la condición de transposición figurativa, diremos que las dos formas del contenido (las formas modales, pasionales y axiológicas, por un lado; las formas de interacciones corporales, por otro lado) son, respectivamente, la inmanencia y la manifestación las unas de las otras.

Las dos condiciones reunidas permiten precisar que en razón de su naturaleza figurativa y corporal, la huella añade al marcaje, cuya manifestación figurativa asegura, propiedades temporales, transformando al mismo tiempo la dirección regresiva en memoria y la dirección progresiva en anticipación.

Para resumir este punto diremos que la articulación entre la dimensión sintagmática de las prácticas y la dimensión figurativa de las huellas supone, primero, el establecimiento de dos relaciones semióticas de expresión, y luego, de dos relaciones de manifestación:

E1: las figuras de articulaciones sintagmáticas//C1: los valores práxicos (modales, pasionales, etc.).

E2: las figuras de huellas corporales//C2: las formas de interacciones corporales.

Plano de la expresión: E2 es la manifestación de E1// Plano del contenido: C2 es la manifestación de C1.

El conjunto puede tomar la forma, en algunas realizaciones textualizadas, de un sistema semisimbólico: (E2 es a E1 lo que C2 es a C1), pero esa realización implica una clausura que 
no es apropiada para el análisis de las prácticas propiamente dichas, porque esas correlaciones únicamente tienen validez para una zona crítica determinada y no para el conjunto del curso de acción.

\section{El curso del sentido y su acomodación}

La cuestión que se plantea es la del sentido práctico, elaborado y captado al mismo tiempo, en su curso. Las secuencias canónicas y los modelos de análisis no pueden ser "aplicados" de la misma manera al sentido práctico y al sentido textual. En el segundo caso, pertenecen a la competencia de un observador externo, a un intérprete que no estaría directamente implicado; en el primer caso, en cambio, los modelos están disponibles en la competencia de un actante implicado en el curso de acción, para participar en el curso del sentido, aunque entre muchas otras presiones circunstanciales y débilmente modelizables.

Tratar las prácticas como lenguajes equivale a reconocerles también una dimensión "epi-semiótica"1, que no es un verdadero «metalenguaje», pero que permite al menos al operador ejercer a la vez un control (cognitivo) y una regulación (práctica) sobre el curso de acción. Además, esa dimensión epi-semiótica proporciona un anclaje interno al observador exterior y al analista. Dicha dimensión episemiótica gestiona el conjunto de los procesos que hemos designado globalmente con la expresión de «acomodación sintagmática».

En efecto, la textualidad de una semiótica-objeto, cuya significación está clausurada, reposa a la vez sobre una objetivación y sobre la puesta a distancia de un analista que se sitúa entonces como no implicado en el proceso semiótico de modelización interna, propio de la semiótica-objeto.

A la inversa, la «practicidad» de una semiótica-objeto reposa por principio en el postulado de una dimensión epi-semiótica y de modelización interna, y en la hipótesis de sistemas y de procesos de reglaje inherentes al curso de la práctica misma. Necesitamos partir de la hipótesis según la cual toda práctica comprende una parte de interpretación, una dimensión cognitiva y pasional interna que incluiría todas las operaciones de reglaje de las interacciones, comprendidas las relativas a los valores práxicos, sin importar que esas interacciones sean automáticas o preparadas, programadas o improvisadas, voluntarias o involuntarias.

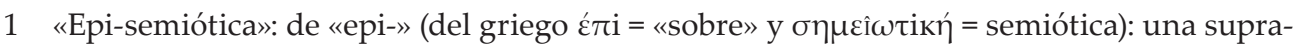
semiótica, sin llegar a ser un metalenguaje; la semiótica de la «episteme», tal vez; de las nociones generales que condicionan las formas de entender y de interpretar el mundo en determinadas épocas [N. del T.]. 
Como esa dimensión cognitivointerpretativa, considerada separadamente, constituye por sí misma una práctica (un curso de acción abierto y fluctuante), resulta de ello que toda práctica comporta por principio una dimensión estratégica integrada, en el sentido en que acomoda al menos dos prácticas: el curso principal y el curso secundario de la práctica interpretativa. No llegaremos a decir, con Bourdieu, que los modelos, las secuencias canónicas y los regímenes tipo no tienen ninguna pertinencia para la comprensión del sentido práctico. Pero sí estaremos de acuerdo en que la práctica no consiste en «ejecutarlos». Funciona más bien como horizonte de referencia y como seguridad respecto de los azares y de las peripecias, así como de los esquemas que ejercen presión persuasiva y de la conducción deontológica o teleológica, para resolver los problemas planteados en la práctica misma.

En el curso de esos reglajes y bajo el control de la dimensión epi-semiótica, especialmente de sus aspectos pasionales y axiológicos, se producen los «marcajes» de los puntos críticos pertinentes, que corresponden a las «huellas» dejadas por las interacciones sobre los cuerpos-actantes.

La organización sintagmática del curso del sentido práctico está, pues, constituida, de hecho, por confrontaciones y por acomodaciones, eventualmente (y solo eventualmente) guiadas por el horizonte de secuencias canónicas, e implica siempre, al menos implícitamente, una actividad interpretativa, sea reflexiva (tendremos que hacer entonces una auto-acomodación o «ajuste») o transitiva si se refiere a un horizonte de referencia tipológica o canónica (y estaremos ahora ante una hetero-acomodación o «programación»).

Este principio es constitutivo para todos los tipos de prácticas sin excepción, comprendidas aquellas que no parecen depender de la heteroacomodación. Por ejemplo, un «protocolo» parece intuitivamente que solo podrá ser programado de manera rígida y enteramente predefinida; pero incluso en el curso de una ceremonia, la puesta en escena previamente más detallada no puede preverlo todo y menos excluir por adelantado los inevitables incidentes del recorrido y un tanto de improvisación. Y justamente en caso de algún incidente, el protocolo hace valer sus derechos para proporcionar respuestas inmediatas y adaptables a situaciones imprevistas, para guiar, en suma, la improvisación.

El caso del «ritual» es más delicado, puesto que su eficiencia se supone que deriva de la estricta aplicación de un esquema y de un recorrido figurativo fijado. Sin embargo, es sin duda el caso en el que mejor se cumple el principio de acomodación estratégica, a condición de ampliar el campo de pertinencia. Para comenzar, el recorrido ritual solo fija una parte de los nudos sintagmáticos de la práctica, aquellos que son pertinentes para una eficiencia simbólica óptima, y todos los demás están sometidos a variaciones cultura- 
les o contingentes. Pero sobre todo, en su principio mismo, un ritual tiene por objetivo proporcionar una solución a un problema surgido en una comunidad. Ese problema puede ser originario y recurrente, y la solución, periódica (como en el caso de la eucaristía); el problema por tratar puede ser también accidental (enfermedad, catástrofe, incidente o intemperie), y la solución será entonces puntual (como en el caso de los rituales terapéuticos africanos); el problema por tratar puede ser, en fin, errático, a la vez recurrente e irregular, como las comidas que marcan las necesidades de convivialidad en el seno de los grupos de trabajo o de ocio.

Protocolosyritualesobedecen, pues, también al principio de la acomoda ción estratégica.

\section{La secuencia de acomodación}

Los procesos de acomodación tienen un doble objetivo: por un lado, el objetivo propio de la práctica y del curso de acción, y por otro lado, el objetivo «hermenéutico», puesto que ambos ayudan a revelar la significación del curso de acción, al mismo tiempo que contribuyen a lograr el objetivo inmediato de la práctica. Toda práctica incluye, pues, zonas de acomodación que toman la forma de una secuencia de resolución $y$ de puesta en forma significante entre dos puntos críticos, marcados, el primero por un defecto de sentido y por una carencia de articulaciones significantes, capaz de interrumpir el curso de acción, y el segundo por una «propuesta» de significación que autoriza la continuación o el relanzamiento.

La «falta de sentido» se debe únicamente al hecho de que no se conoce aún la forma ni el sentido del curso de acción, porque tiene precisamente la forma de una abertura del campo de las modalizaciones y en particular de los posibles de la acción. Esa «falta de sentido» es más precisamente un «defecto modal» que inhibe la propuesta de una significación coherente. La abertura de los campos de modalización resulta directamente de la confrontación de cada práctica con otras prácticas, porque ningún curso de acción puede desarrollarse fuera de situación, en el «vacío semiótico», en abstracto, y sin confrontación con otras.

La secuencia de resolución parte de la experiencia de esos «posibles de sentido", y desemboca en una forma de acomodación, en el segundo punto crítico, el de la «donación de sentido». La secuencia de resolución tendrá la forma siguiente:

<MARCAJE1 - ABERTURA MODAL

- COMPROMISO Y ESQUEMATIZACIÓN

- REGULACIÓN - ACOMODACIÓN

- MARCAJE2>

\section{a) La abertura modal y los «posibles de sentido»}

Es la fase de actualización de la situación-ocurrencia y de la confrontación entre la práctica y su alteridad, donde se hace la expe- 
riencia de la extrañeza (o de la familiaridad), de la congruencia (o de la incongruencia), etc. Encontrarse con otras personas en un ascensor es un ejemplo bien conocido de esa experiencia: la sola condición espacio-temporal que reúne provisionalmente a varios actores comprometidos separadamente en la misma práctica crea una situaciónocurrencia que demanda sentido, y la indeterminación modal suscita un malestar pasajero, hasta la primera palabra o el primer intercambio de miradas, o hasta la llegada al piso marcado. El «malestar» es la primera huella de la secuencia.

\section{b) El compromiso y la esquematización}

Una situación-ocurrencia percibida como portadora de alteridad y de asperezas está sometida a la búsqueda de esquemas y de organizaciones reconocibles con las que los actores sean capaces de comprometerse: búsqueda de una isotopía, de unjuego de roles actanciales, de modalidades dominantes, de latitudes espaciales y temporales, que se pudieran identificar en la intersección de la práctica en curso y otras prácticas potenciales. Esa identificación puede ser facilitada por el recurso a una situación-tipo cuya solución ya se conoce en una perspectiva hetero-adaptativa, y tenemos que ver en tal caso con una esquematización; o conducida prospectivamen- te, llevada por el compromiso de los actores, nos conducirá entonces a la proyección de un esquema innovador y específico, en una perspectiva auto-adaptativa. En el equilibrio entre esas dos tendencias se juega la alternativa o la combinación de las dos formas de la acomodación: el ajuste y la programación.

\section{c) La regulación}

Es el momento en que la solución (la forma eficiente) es proyectada sobre la ocurrencia. La propiedad principal de la regulación es la de ser interactiva e indefinidamente recursiva. Es una fase en la que el peso axiológico y la legitimidad cultural de los esquemas utilizados actúan sobre las relaciones de fuerza: si no son reconocidos o admitidos por los otros actores, la regulación fracasa, y deja lugar a otras tentativas. Más precisamente, el «peso» de los esquemas propuestos es un peso modal en el sentido en que modifica el equilibrio de los querer-hacer, de los saber-hacer, y de los poder-hacer de los actores.

En el curso de la subida del ascensor, por ejemplo, una combinación de miradas, de sonrisas y frases puede ser recibida tanto como una amable diversión que como una intrusión insoportable; en un caso, los querery saber-hacer se ponen de acuerdo; en el otro caso, la propuesta es recibida como la manifestación de un querer-hacer inoportuno. 
La regulación explora posibilidades de interacción, las testifica y las negocia.

\section{d) La acomodación}

«Acomodación» significa aquí, muy precisamente, que el conjunto de la situación-ocurrencia forma ahora, en este momento, un mismo conjunto de prácticas coherentes, y que esa coherencia ha sido obtenida por la articulación estratégica de una de las prácticas con las otras, y recíprocamente. «Acomodación» designa, pues, a la vez, el resultado, la forma sintagmática aplicada a la práctica en curso, y el proceso que a eso conduce. Para volver a la situación del ascensor, si una de las personas propone a una anciana ayudarla con sus paquetes embarazosos, y si la anciana acepta, la acomodación da a la práctica en curso de esa persona la forma de una entre-ayuda pasajera. Referida al «malestar» que ha precedido, la huella resultante de la acomodación exitosa produce ahora un «archivo» y una distensión corporal.

La acomodación termina la secuencia, pero muy precisamente como un relanzamiento del curso de acción y no como una clausura del sentido.

\section{Modelo de la acomodación eficiente ${ }^{2}$}

El curso de acción óptimo tiene un doble objetivo (pragmático y cognitivo). Podemos considerar que el logro del objetivo hermenéutico (comprender el sentido de la acción en curso al mismo tiempo que se realiza) caracteriza la situación, como mínimo, aquella justamente con la que uno se contenta cuando el objetivo práctico todavía no es accesible. La acomodación del curso de acción queda entonces reducida a la búsqueda de la eficiencia y de la prosecución de la acción. En otros términos, la eficiencia elemental -el grado mínimo de acomodacióngarantiza a la vez la cursividad y la significación de la práctica.

La significación de los cursos de acción se inscribirá en sistemas de valores prácticos, cuyas «valencias constitutivas» es preciso identificar ahora, y muy especialmente la cualidad intensiva y extensiva de las percepciones y de las impresiones del operador, las cuales dan acceso a los valores en construcción y le permiten participar directamente en el marcaje de las huellas. Las valencias que aquí nos interesan ya han sido anteriormente invocadas a través de los dos modos principales del proceso de acomodación: el modo hetero-adaptativo y el modo auto-adaptativo. Como ca-

2 Para un mejor conocimiento de la «acomodación», véase Fontanille, 2014, capítulo III, p. 150 y ss. [N. del T.]. 
da práctica se compone de una parte de acomodación hetero-adaptativa y de una parte de acomodación autoadaptativa, cada proceso de acomodación opera en tensión entre esas dos tendencias, y las soluciones conservadas pueden, por tanto, ser definidas dentro de una estructura tensiva.

El curso de las prácticas se desarrolla entre una presión reguladora externa (la programación) y una presión reguladora interna (el ajuste), entre el reglaje a priori y el reglaje en tiempo real, o sea a posteriori. La programación de las prácticas, y especialmente su programación discursiva, previa o paralela al curso de acción, sea oral, escrita o icónica, es una de sus dimensiones mejor instituidas, particularmente en el caso de las prácticas de trabajo y de transformación de objetos materiales: modos de empleo, procedimientos, indicaciones y señales de seguridad, cuadernos de cargo, son algunas de las manifestaciones posibles.

Pero la programación práctica debe acomodarse también a los azares y a las interacciones en tiempo real, que constituyen el objeto de ajustes permanentes en la interacción, en todo punto del curso de acción: ajuste con el entorno, con las otras circunstancias y con las interferencias de las otras prácticas. Ninguna conducta, ningún rito puede desarrollarse sin reglaje en tiempo real, en el tiempo mismo del curso de acción; ningún procedimiento, incluso perfectamente programado, escapa a ese tipo de ajustes, que pueden afectar igualmente a rutinas arraigadas como promover innovaciones inesperadas.

La percepción de la valencia de programación es extensiva porque se aprecia en función del tamaño del segmento programado, de su complejidad, de su duración, del número de bifurcaciones y de alternativas tomadas en cuenta, así como por la capacidad de anticipación global que comporta. La percepción de la valencia de ajuste es intensiva porque capta la fuerza del compromiso del operador en su práctica, de una presión interna de interés, de afecto participativo, y de adhesión a la acomodación en curso. El destello, el acento de intensidad están del lado de la valencia del ajuste y de la abertura, mientras que la restricción, la estabilidad en el tiempo y en el espacio están del lado de la valencia de programación y del cierre. En razón de la tensión entre esas dos valencias, algunas prácticas parecen más «abiertas»y otras más «cerradas».

La reunión de las dos valencias perceptivas graduables puede ofrecerse en el seno de una misma estructura tensiva, en la cual pueden ser definidas un número determinado de posiciones axiológicas, en particular las posiciones y los valores extremos: 


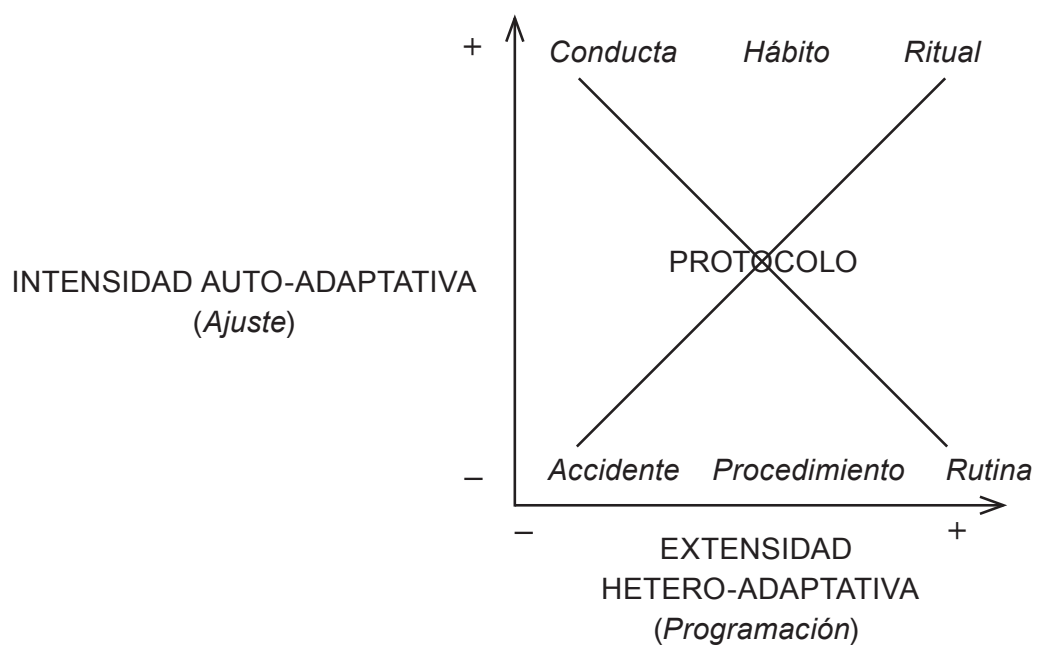

\section{Huella de las interacciones prácticas}

Si consideramos ahora los cuerposactantes implicados en esas prácticas, podemos examinar la acomodación sintagmática de las interacciones bajo una iluminación complementaria. En cuanto cuerpos, los cuerpos-actantes contribuyen a la acomodación de las tensiones retrospectivas y prospectivas del curso de acción. Y para hacerlo, en cuanto cuerpos-actantes, entran en interacción, y esas interacciones inducen marcajes corporales, que son las huellas. En la dirección retrospectiva, se trata de la constitución de una memoria figurativa de interacciones, $y$, en la dirección prospectiva, de una capacidad de anticipación de las interacciones. Las dos orientaciones nos parecen indisociables y su asociación está en la base misma de la definición de las huellas y de los «puntos críticos» a los cuales las huellas corresponden. La participación de los cuerpos-actantes en la acomodación sintagmática será examinada a través del proceso de la huella corporal.

\section{La huella como significante de las interacciones pasadas y venideras}

La huella reposa en un modo de funcionamiento semiótico particular, y podemos comenzar por la huella sobre los cuerpos-envoltura, cuya aproximación parece intuitivamente más accesible.

En ese caso, en efecto, la huella resulta de un contacto entre dos cuerpos, y más precisamente, entre dos de sus envolturas, bajo el efecto de una fuerza que los acerca uno a otro. En ese sentido, la huella no es más que la traza de un ajuste en el curso de una interacción. Sería inexacto concluir de ahí que la huella es por ese mismo hecho una expresión o un significante del otro cuerpo. Si la huella expresa algo, no puede ser más que el esfuerzo 
y el proceso de ajuste entre dos cursos de acción prácticos, vía las envolturas de los cuerpos-actantes.

Por esta definición en términos de ajuste, se puede ver que esta concepción de la huella puede ser extendida inmediatamente a otros tipos de huellas, que conciernen a otras figuras distintas del cuerpo-envoltura. El modo de significar de la huella podría ser analizado en general en los términos siguientes:

- La huella solo funciona por contigüidad espacial o temporal. Contigüidad no significa exhaustividad, y por tanto la huella puede ser parcial e incluso discontinua. Pero allí donde hay huella ha habido y habrá contigüidad, aunque haya sido imperfecta.

- Una huella solo se puede identificar si se separan los dos cuerpos en interacción. La huella implica, pues, el retiro y la ausencia del cuerpo que ha interactuado o que interactuará con el cuerpo marcado; y en ese sentido implica un funcionamiento semiótico elemental: es algo que vale (que de alguna manera nos esforzamos en establecer) por otra cosa ausente ${ }^{3}$.

- Esa ausencia se produce necesariamente después o en previsión de una presencia (de la que la huella guarda o prefigura la traza); la figura de la huella sintetiza una micro-secuencia de interacción, al hacer coexistir dos momentos de dicha interacción, uno potencializado (la presencia anterior o posterior), y el otro actualizado (la ausencia actual).

- El lazo entre la presencia potencial y la ausencia actual, a través de la forma de la huella, supone un marcaje intensivo específico, que corresponde a un "punto crítico» de la interacción. El marcaje no es más que una determinación local, retensiva y protensiva. La huella le añade, por el juego de los modos de existencia, una dimensión temporal.

En la huella, nada disjunta los dos cuerpos en interacción, a no ser un cambio de estatuto existencial (potencializado/actualizado), y un desembrague espacio-temporal. La huella realiza, de hecho, dos condiciones que son explotables bajo formas de configuraciones temáticas y narrativas: (i) una contigüidad espacial y/o temporal perfecta o imperfecta, con o sin solución de continuidad; (ii) y una necesaria basculación de los modos de existencia.

La primera condición está tan bien realizada que la huella se considera testimonio, prueba y firma individual: a ese respecto, asegura la continuidad

3 Alusión a la definición de «signo» de San Agustín: «Signum est res quæ, praeter speciem quam ingerit in sensibus, aliud aliquid ex se faciens in cogitationem venire» (El signo es una cosa, que además de la especie que inscribe en los sentidos, hace que alguna otra cosa venga al pensamiento). De doctrina christiana, II, 1.1. [N. del T.]. 
entre los dos estatutos sucesivos o concomitantes del cuerpo-actante. Con la segunda ocurre lo mismo, pues por el tiempo que la mano permanezca posada sobre la superficie en la que marca sus trazas, no hay, estrictamente hablando, huella. Es necesario que las dos facetas de la huella sean una actual y la otra potencial, a la vez separadas por su modo de existencia respectivo, y enlazadas por la fuerza de un marcaje, para que pueda funcionar como signo e implicar así procesos interpretativos y persuasivos, estrategias de reminiscencia y de testimonio, etc.

Hemos denominado «marcaje» a ese principio sintagmático general de modificación de las entidades semióticas por las interacciones anteriores o posteriores: ese fenómeno sintagmático supone al menos que esas entidades, además de su rol puramente formal, obedezcan a un principio de identidad y de permanencia. La cadena de marcajes constituye la memoria y la anticipación de las interacciones. En fin, en el caso particular de las entidades figurativas, y especialmente de las figuras tratadas como cuerpos-actantes, los marcajes son operaciones que producen huellas, y la capacidad de memoria y de anticipación corporales de las semióticas-objetos está constituida en ese caso por la red de esas huellas.

En el caso particular de los cuerpos-envolturas, esa red de huellas forma lo que hemos llamado la superficie de inscripción, que está constituida por la totalidad de los recuerdos y anticipaciones de estimulaciones, de inte- racciones y de tensiones recibidas por el cuerpo-envoltura. Los otros tipos de cuerpos-actantes (el cuerpo-cavidad, el cuerpo-punto, el cuerpo-carne) acogen igualmente redes de huellas, que exploraremos más adelante.

Este conjunto conceptual: marcaje, huella y memoria/anticipación figurativas hay que incluirlo en una sintaxis figurativa de las semióticas-objetos, integrada a su vez a la semiótica de las prácticas.

\section{La huella como significante en busca de su significado}

La semiótica de la huella es generalizable en el sentido en que concierne a la función semiótica en su acepción más amplia. El problema por tratar ahora es el del proceso de interpretación de las huellas, sabiendo que esa interpretación participa directamente de la regulación de los cursos de acción y de la dimensión epi-semiótica de las prácticas.

El problema será abordado a partir de un caso emblemático de ese proceso: el dispositivo de interpretación puesto en escena por Kafka en su obra En la colonia penitenciaria: un condenado por haber quebrantado una regla o una ley es inmovilizado en una máquina, que va a ejecutar la sentencia; esa máquina inscribe sobre la piel y en la carne del condenado, gracias a una multitud de agujas, el texto de la ley que ha quebrantado y que justifica su condena, y eso durante doce horas. El verdugo debe «dactilografiar» previa- 
mente el contenido de la inscripción en la máquina, ponerla luego en marcha, y vigilar que el condenado soporte el suplicio por un largo tiempo. El objetivo es llegar por lo menos al momento en el que el condenado pueda leer desde el interior y en el sufrimiento de su carne, el contenido de aquello que se inscribe sobre su piel y que se graba en su carne. El marco de ese suplicio es una interacción social: en general, el condenado es un soldado que, por ejemplo, ha faltado al respeto a uno de los cuadros militares de la colonia, y el castigo infligido es una respuesta a esa infracción, y se aplica hasta que el infractor haya reconocido desde el interior la razón de su falta.

Ese ritual penitenciario es ejemplar: la sentencia, inscrita en la superficie exterior de la piel del condenado por la máquina, es también reconocida y leída desde el interior por el cuerpo torturado, pero con un cambio de estatuto; por un lado, la inscripción exterior proporciona la descripción de la regla que ha sido quebrantada, mientras que por otro lado, la lectura interior está indisolublemente asociada a la aplicación de la sentencia (el sufrimiento y la muerte). El sufrimiento está a su vez modulado en una secuencia que manifiesta la conversión en cuestión: simple dolor superficial al principio, se convierte en comprensión íntima y carnal al final.

Paralelamente, los efectos de ese sufrimiento y de su lectura interior deben ser legibles desde el exterior, y todo el público que asiste a esa sesión de tortura semiótica espera con impaciencia el momento en que los efectos de la lectura carnal e interior se manifiesten en el rostro del ajusticiado. El relato de Kafka es muy preciso sobre este punto: el condenado no conoce la sentencia, el suplicio de la inscripción dura doce horas hasta la muerte; pero a la hora sexta, el rostro del condenado se alegra, pues logra al fin leer el enunciado en las sensaciones de su carne.

El segmento pertinente está delimitado por dos «puntos críticos», que corresponden a dos versiones diferentes de la huella: desde la primera hora, se trata de la huella sobre la superficie de inscripción; a partir de la hora sexta, se trata de la huella carnal. La inscripción recapitula los efectos y las consecuencias de las interacciones anteriores que han conducido al suplicio, y anticipa y motiva el suplicio mismo. La huella carnal recapitula los efectos y las consecuencias del suplicio y anticipa y motiva la agonía que vendrá, convertida en significante.

Las dos dimensiones, por un lado la de la inscripción de la regla quebrantada, y por otro, la de la aplicación de la sentencia (el castigo) están enlazadas de dos maneras complementarias: (i) en «producción», se hallan en relación de contigüidad, gracias a la superficie de inscripción (la piel del condenado) que les es común, pero como interfaz entre un interior y un exterior; (ii) en «recepción», están en relación a la vez en el plano pasional y en el plano cognitivo. Por un lado, el sufrimiento experimentado en el in- 
terior es provocado por el dispositivo exterior, y por otro lado, al momento de la conversión del sufrimiento en «comprensión», se instala la fase interpretativa suscitada por la huella.

Esa interfaz cumple, pues, en el caso examinado, un verdadero rol performativo: la traza exterior es una descripción (en forma de una escritura y de grafismos decorativos complementarios), pero su inscripción es también una acción que modifica el estado del cuerpo por medio de la traza interior. Podemos, entonces, considerar que las dos trazas sobre las dos fases de la envoltura corporal forman una sola y misma red de huellas, en cuyo seno se produce, entre los dos puntos críticos identificados más arriba, una conversión entre las huellas del cuerpoenvoltura y las del cuerpo-carne. La red de huellas, comprendida la de la conversión, adquiere ahora la estructura de un acto de enunciación (aserción, asunción y transformación). La conversión en cuestión, que le proporciona al actor el sentido del curso de acción, permite igualmente a ese curso proseguir más allá del momento de «comprensión», y hasta la muerte.

Asimismo, sobre la pantalla de cine son proyectadas formas y figuras, que son percibidas por el cuerpo «tout percevant» [que todo lo percibe] del espectador, como una enunciación que transforma su entorno inmediato y su campo de presencia sensorial en un universo de ficción ambiental y envolvente, en cuyo se- no las inscripciones de superficie son convertidas en animaciones de una carne imaginaria. Igualmente, sobre la página del poema son inscritas formas escritas, que son transformadas al momento de la lectura, por el cuerpo del lector, en un universo poético que está a la vez «detrás» de la página y «envuelto» en los límites de su propio cuerpo: el desembrague por proyección e inversión está actuando aquí claramente, e instaura el campo de enunciación donde la interpretación puede desplegarse.

En el curso de la tortura semiótica relatada En la colonia penitenciaria, la envoltura de superficie no es solamente una interfaz entre un exterior y un interior; es también, por efecto del desembrague (proyección-inversión), el lugar de una conversión entre dos regímenes diferentes de la huella (cuerposenvoltura/cuerpos-carne), que da cuenta más concretamente de la conversión de las expresiones en contenidos: las expresiones son inscritas en superficie y deben ser resentidas e interpretadas por la carne sensible, y, lejos de ser una simple correlación formal, esa conversión asume la vía de los placeres y de los sufrimientos del cuerpo: esa sería, en otros términos, la puesta en escena de una conversión de manifestaciones exteroceptivas en vivencias interoceptivas, gracias a la mediación del cuerpo propio y a las operaciones (proyección-inversión) del desembrague del que es objeto. 


\section{Figuras del cuerpo y tipología de las huellas}

\section{a) De las formas de la huella a los procesos interpretativos}

Hemos definido las huellas como un efecto particular del marcaje de los puntos críticos del curso de acción: desde los marcajes propios de los cuerpos hasta la dimensión figurativa de las interacciones entre cuerposactantes. La cuestión que se plantea, por consiguiente, es la de la eventual especificidad de las huellas que corresponden a cada uno de los tipos de figuras del cuerpo y a cada uno de los tipos de movimientos concordantes con esas figuras del cuerpo.

La tipología de las huellas que proponemos aquí es, por consiguiente, una tipología de las modificaciones por marcaje que puede soportar cada uno de los tipos de figuras del cuerpo afectado por el tipo de movimiento que le corresponde. La concordancia entre los tipos de figuras del cuerpo, los tipos de movimiento y los tipos de huellas es una condición para que la huella sea interpretable. La cuestión de los marcajes que son producidos por combinaciones discordantes será examinada ulteriormente. La interpretación, en la ocurrencia, es particularmente la de participantes en interacciones, sobre la dimensión epi-semiótica de las prácticas en vista de la acomodación del curso de acción.
A cada tipo de «concordancia» corresponderá, por consiguiente, a la vez un tipo de huella y un tipo de interpretación de la huella en cuestión. A fin de cuentas, la tipología hacia la cual tendemos será una tipología de los «modos de significar» de las huellas, que se fundará principalmente en una identificación del soporte semiótico y en las exigencias que él impone a la interpretación.

Las huellas producidas por deformaciones son inscritas en cuerposenvolturas; y están destinadas a ser «leídas» y descifradas porque se dan a captar como figuras de superficie. «Inscripciones», «superficie de inscripción», «desciframiento» son aquí denominaciones aproximadas para un solo y mismo fenómeno, a saber, la transformación de la envoltura de un cuerpo en un soporte semiótico que pueda acoger una red de manifestaciones plásticas tridimensionales (dos dimensiones para la disposición de las inscripciones-trazas y deformaciones, y una tercera para la profundidad de las inscripciones).

Esa red inscrita sobre una superficie es interpretada entonces como un arreglo sintagmático de trazos y de caracteres, que deben ser considerados como la manifestación actual sea de interacciones anteriores con otros cuerpos, sea de interacciones que vendrán posteriormente. Las trazas de desgaste (de usura) en un objeto de uso ilustran ese tipo de 
huellas: resultan de una multitud de manipulaciones acumuladas en el curso de prácticas de uso repetidas; esas manipulaciones modifican la envoltura del objeto, de una manera que se distingue de otros tipos de manipulaciones o de prácticas (ruptura, accidente, desmontaje o desglose, grabado, etc.) $\mathrm{y}$ en ese sentido, y porque permiten reconstituir una gama de prácticas bien identificadas y distintas de otras gamas de prácticas, esas huellas pueden ser interpretadas como trazas de desgaste. La «red» de las huellas de superficie corresponde, pues, a una clase de huellas homogénea, o sea, isótopa, desde el momento en que puede ser objeto de una lectura coherente.

Las huellas «enterradas» en la carne móvil resultan de marcajes sensorio-motores: el marcaje procede o de un acento de intensidad, emoción, dolor o esfuerzo, o de la iteración de una rutina instalada por el uso, pero en los dos casos singulariza un esquema sensoriomotor que será susceptible de ser reactualizado posteriormente. El marcaje sensorio-motor tiene de particular el hecho de asociar a una sensación motriz bien identificada un conjunto de figuras y de sensaciones características de la situación figurativa en cuyo seno tiene lugar la experiencia sensorio-motriz.

La riqueza y la extensión de esas configuraciones asociadas expresan la eficacia del marcaje. Ese conjunto de configuraciones asociadas y enlazadas por la sensación motriz constituye un «haz» sensorio-motor. Uno de los ejemplos más conocidos de ese tipo de configuración es aquel que resurge en la memoria sensorial del narrador de En busca del tiempo perdido, en el tomo titulado El tiempo recobrado, cuando tropezando con los adoquines desiguales del patio de la residencia de los Guermantes, enlaza con la misma sensación que experimentó con los adoquines de la plaza de San Marcos en Venecia, y esa huella sensorio-motriz conlleva el conjunto de sensaciones que había «anudado» en un haz configurativo: un instante y un lugar de Venecia han sido así resucitados.

Las huellas sensorio-motrices no son legibles ni directamente observables. Su soporte es la estructura materialdelcuerpo,elcuerpo-carne, cuya plasticidad permite aprendizajes, así como la formación de esquemas motores a partir de las contracciones y dilataciones que lo animan:esquemassensorio-motores se constituyen en la experiencia sensible, y algunos de esos esquemas son marcados para ser restituidos. Esas huellas están, pues, «escondidas», enterradas, en la carne móvil en vías de aprendizaje, y serán «desenterradas» y sacadas a la luz algún día. En el momento de la operación de desenterramiento, arrastrarán con ellas 
todas las configuraciones sensibles asociadas, la totalidad del haz de percepciones y de acciones que ha sido objeto de un marcaje asociativo por la fuerza del lazo impuesto por la huella sensorio-motriz.

En el cuerpo-cavidad, las agitaciones diseñan escenarios, disposiciones espacio-temporales y distribuciones de roles actoriales. Esas agitaciones esquematizadas, sea por la intensidad de la emoción que de ella emana, sea por la repetición de su aparición, dejan como consecuencia huellas configuradas en forma de escenas y de acontecimientos. Las calificaremos como huellas diegéticas, cuyo modo de significar será necesariamente temático y narrativo (o sea: diegético). La formación de la huella es una presentación de escena (la instalación de una situación y de los acontecimientos que la transforman), y su interpretación será una representación, que apuntará a la reconstitución, en forma de una enunciación de tipo narrativo, de la escena en cuestión.

Por el lado del cuerpo-punto, el movimiento de desplazamiento induce relaciones entre posiciones corporales. Ese sistema de posiciones potencializadas, memorizadas y referidas a la posición actual del cuerpo-punto es típicamente de naturaleza deíctica. Tal sistema se halla en constante revisión, en la medida en que, por la definición, la referencia deíctica es siempre relativa a la actualidad efímera del cuerpo de referencia. Pero ocurre también que algunos de los estados del sistema en transformación pueden ser objeto de marcajes, sea por efecto de un acento de intensidad emocional, o también en razón de cualquier iteración. Esos marcajes producen también huellas, que denominamos «huellas deícticas» del cuerpo-punto. Desde ese momento, la memoria de las huellas deícticas constituye, como las piedrecillas de Pulgarcito, una cadena de pistas que pueden formar itinerarios. La interpretación de esas huellas y su enunciación procederán entonces a través de las pistas de los puntos marcados, y de la reconstitución de las series de pistas: la forma específica de los conjuntos de las huellas deícticas constituye un itinerario.

Es posible ahora proponer una tipología de las huellas y de sus modos de significar, que podemos proyectar para terminar sobre la tipología concordante de las figuras del cuerpo y de las figuras del movimiento ${ }^{4}$ :

4 Para una ampliación de esta problemática sobre la huella y su tratamiento, véase Fontanille, 2008, tercera parte, capítulos 1 y 2; del mismo autor: "Cuerpo y sentido". Lima: Universidad de Lima (de próxima publicación) [N. del T.]. 


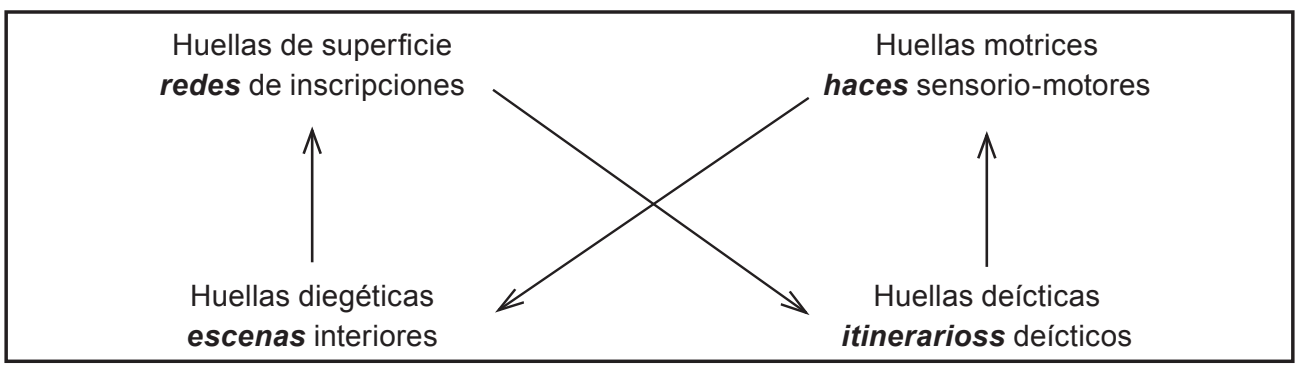

PRESENTACIÓN Y REPRESENTACIÓN

PISTAS Y SERIACIONES

\section{b) Concordancia, discordancia y reglas de interpretación}

La elaboración de este modelo con cuatro estratos tipológicos reposa en una homologación entre las cuatro dimensiones, cuya declinación concreta es, para cada una de las cuatro posiciones del cuadrado semiótico, lo que hemos llamado la «concordancia» entre figuras.
La concordancia y la discordancia son propiedades de la asociación de figuras corporales tomadas de cada una de las cuatro dimensiones, de suerte que cada una de las cuatro posiciones del cuadrado semiótico en cuestión se convierte en una "posición de concordancia o de discordancia» entre dimensiones figurativas.

ENCRIPTAJES Y DESENCRIPTAJES

OCULTACIONES Y DESOCULTACIONES

\begin{tabular}{|cc|}
\hline $\begin{array}{c}\text { Huellas de superficie } \\
\text { redes de inscripciones }\end{array}$ & $\begin{array}{c}\text { Huellas motrices } \\
\text { haces sensorio-motores }\end{array}$ \\
\hline $\begin{array}{c}\text { Deformaciones } \\
\text { Cuerpo-envoltura }\end{array}$ & Mociones íntimas \\
Cuerpo-cavidad & Cuerpo-carne \\
Agitaciones & Cuerpo-punto \\
\hline Huellas diegéticas & Desplazamientos \\
escenas interiores & $\begin{array}{c}\text { Huellas deícticas } \\
\text { itinerarios deícticos }\end{array}$ \\
\hline
\end{tabular}


Ese principio de concordancia/discordancia nos permite, por ejemplo, afirmar que las «agitaciones» son movimientos propios de un cuerpocavidad (y no de un cuerpo-carne), que la esquematización y el marcaje de esas «agitaciones» producen específicamente «huellas diegéticas» (y no inscripciones de superficie), y apelan a estrategias de enunciación del tipo «presentación y representación de escena» (y no de demarcación deíctica).

El principio de concordancia recubre de hecho a la vez un proceso de engendramiento deductivo (desde el punto de vista de la producción de la configuración) y una condición de isotopía (desde el punto de vista de la interpretación de la configuración). Hay ahí, en efecto, a la vez un «recorrido generativo» y una «isotopía» entre las cuatro dimensiones en cada una de las posiciones. Por ejemplo, cuerpo-cavidad $>$ agitaciones $>$ huellas diegéticas $>$ presentación de escena están en ese sentido en una relación de isotopía y en una cadena concordante de engendramiento.

La discordancia implica funcionamientos alótopos o atípicos que exigen condiciones suplementarias y específicas para que sean significantes e interpretables.

Si se considera, por ejemplo, que un rostro es un cuerpo-envoltura dedicado a recibir inscripciones, cifrables y descifrables, entonces tenemos que ver con una construcción isótopa. El nombre de esa isotopía podría ser en ese caso la «fisonomía» del rostro, y por el tiempo durante el cual las variaciones de formas y de rasgos del rostro permanecieran en los límites de las inscripciones propias de los cuerpos-envolturas, la fisonomía podría permanecer reconocible o volverse irreconocible, aunque siguiera siendo una «fisonomía». En otros términos, la concordancia entre el tipo de figura del cuerpo, el tipo de movimiento y el tipo de huella, garantiza la isotopía de la configuración.

En cambio, si no está prohibido aplicar a un rostro movimientos tomados de las mociones íntimas del cuerpocarne (dilataciones y contracciones), como también las huellas sensoriomotrices que esquematizan estas últimas, hay que esperar que esos movimientos produzcan efectos de una naturaleza totalmente diferente, porque la configuración obtenida no es isótopa, y los movimientos y huellas, al escapar a los límites de la concordancia con el cuerpo-envoltura, destruyen la «fisonomía» del rostro. Es posible, entonces, considerar que el resultado no es interpretable, y concluir que no tiene sentido. Es igualmente posible continuar con la interpretación de esa nueva configuración pero, en ese caso, es preciso explotar registros de variación específicos, capaces de motivar la ruptura de isotopía, y principalmente la conversión del régimen propio del cuerpo-envoltura en el régimen del cuerpo-carne. En el caso invocado, puede ser un género (lo fantástico o la ciencia-ficción), un estilo (el morfismo, típico de las puerilidades visuales de la 
televisión), un tema de intriga atípico (las deformaciones patológicas del rostro de Elephant Man), etc.

De la misma manera, se pueden proyectar sobre un sistema de marcas deícticas huellas diegéticas y toda la agitación y la distribución de un microcosmo de actores, de lugares y de acontecimientos. Pero hace falta, entonces, para dar cuenta de la ruptura de isotopía, y de la conversión del cuerpo-punto en cuerpo-cavidad, convocar ya convenciones de género (lo maravilloso o lo fantástico) o también convenciones de género sostenidas por un dispositivo técnico de visualización que autorice tales variaciones de escala (microscopía, zoom en un sistema de información geográfica, etc.), como es el caso de las prácticas médicas o científicas.

La cuestión de la concordancia y de la discordancia entre las cuatro dimensiones del modelo tiene, pues, una gran virtud heurística, y constituye una restricción y una alternativa portadoras de consecuencias particularmente significativas en términos de estrategias enunciativas. En la colonia penitenciaria, la conversión de las huellas sobre una superficie de inscripción en huellas sensorio-motrices, y de los sufrimien- tos de la carne en texto descifrable, y recíprocamente, constituye incluso el resorte principal de la intriga.

No se trata ahora de distinguir entre un funcionamiento «normal» o canónico y un funcionamiento «anormal»o idiosincrásico del modelo. En cambio, es claro que una configuración construida sobre asociaciones concordantes encuentra su motivación en sí misma, puesto que las cuatro dimensiones figurativas que la componen están enlazadas por una continuidad deductiva e isotópica, mientras que una configuración discordante, en razón de la ruptura de isotopía, debe buscar su motivación en otros registros distintos de aquellos cuatro que proporcionan las dimensiones figurativas de los cuerpos y de las huellas, especialmente los registros de género y de estilo.

\section{Referencias}

Fontanille, J. (2008). Soma y sema. Figuras semióticas del cuerpo. Lima: Universidad de Lima, Fondo Editorial.

Fontanille, J. (2014). Prácticas semióticas. Lima: Universidad de Lima, Fondo Editorial. 